\title{
МЕТОДЫ АНАЛИЗА И ОЦЕНКИ ЛОГИСТИЧЕСКИХ ЗАТРАТ
}

\author{
(c) 2019 Гизатуллина Ольга Михайловна \\ кандидат экономических наук, доцент департамента «Учет, анализ и аудит» \\ Финансовый университет при Правительстве Российской Федерации, Россия, Москва \\ E-mail: olgasergee@mail.ru
}

Для эффективности реализации программы «Цифровая экономика Российской Федерации» важным инструментом будет цифровая логистика, обуславливающая управление человеческими, материальными, информационными и финансовыми потоками с целью их оптимизации для решения задачи минимизации затрат с применением современных информационных технологий.

Ключевые слова: иифровая логистика, логистические затраты, искусственные нейронные сети, метод множественной регрессии.

Российское правительство определило на ближайшие годы программу «Цифровая экономика Российской Федерации», содержащую направления цифровизации российской экономики.

Для эффективности реализации программы важным инструментом будет цифровая логистика, обуславливающая управление человеческими, материальными, информационными и финансовыми потоками с целью их оптимизации для решения задачи минимизации затрат с применением современных информационных технологий [1].

Стратегические направления цифровой логистики связаны с интеграцией Российской Федерации в международные транспортные системы, а транспортные и логистические системы являются ключевыми факторами экономической конкурентоспособности страны. Целями цифровой логистики являются повышение транспортного потенциала и внешнеторгового оборота Российской Федерации; развитие смешанных перевозок; повышение эффективности управления транспортной инфраструктурой.

Целевая модель цифровой логистики- это динамическая открытая бизнес-система, основанная на формировании юридически независимыми экономическими субъектами единого информационного пространства с целью совместного использования своих технологических ресурсов для реализации всех этапов работ по выполнению заказа клиента от источников первичного сырья до передачи продукции конечному потребителю [1].

В современном мире цифровизации подвержены все направления экономики, в том числе логистика. Стремительное развитие цифровой логистики связано со снижением логистических затрат. Повышение эффективности логистических инфраструктур остается важнейшей задачей в сегодняшних условиях глобализации экономики.

Конкурентоспособность экономических субъектов на рынке определяется множеством факторов. Важнейший фактор- это адекватные затраты, в том числе логистические. Поэтому каждый шаг снижения расходов экономическими субъектами необходимо оценивать в совокупности с влиянием на текущие обороты и стратегию.

Анализ и оценка логистических затрат экономического субъекта является средством достижения высоких финансовых результатов и влияет на снижение затрат посредством распространения на все его элементы управления.

Эффективное управление логистическими затратами должно реализовываться на всех этапах управленческого цикла: прогнозирования и планирования, организации, координации и регулирования, учета до контроля и анализа. И процесс этот носит циклический характер.

Основные принципы управления логистическими затратами экономических субъектов выработаны практикой деятельностью. Перечислим сформированные практикой принципы управления логистическими затратами:

- системный подход к управлению затратами;

- единство методов, принятых на разных уровнях управления затратами;

- управление затратами на всех стадиях жизненного цикла продукта - от создания до 
утилизации;

- сочетание снижения затрат с высоким качеством продукции и услуг;

- оптимизация затрат;

- широкое внедрение эффективных методов снижения затрат;

- информатизация процесса управления затратами;

- повышение заинтересованности участников бизнес- процесса в снижении логистических затрат.

Основой для поиска путей снижения логистических затрат и является анализ логистических затрат, позволяющий разработать пути обеспечения конкурентных преимуществ экономического субъекта.

Анализ логистических затрат возможен при:

- обоснованной классификации затрат, включаемых в схему анализа;

- определении центра ответственности за логистическими затратами;

- выявлении сосредоточения логистических затрат в пределах центра их концентрации;

- отнесение логистических затрат на конкретные факты финансово- хозяйственной деятельности;

- рассмотрение логистических затрат в виде единого потока, соответствующего конкретному бизнес-процессу;

- рассмотрении стоимости логистических затрат, как суммы, которую оплачивает потребитель продукции;

- классификации логистических затрат по признакам для четкого определения методов диагностики затрат.

Для анализа и оценки логистических затрат можно использовать методы интеллектуального анализа данных (Методы DATA MINING). На его основе можно получить модели, позволяющие лучше понимать данные и предсказывать их поведение. В таблице 1 представим методы интел- лектуального анализа логистических затрат.

Интеллектуальный анализ данных позволяет обрабатывать больший объем информации и выявлять тенденции, помогающие принять решение. Современные бизнес- требования привели от поиска информации и статистического анализа данных к более сложному интеллектуальному анализу [2].

Задачи интеллектуального анализа данных:

- классификация;

- кластеризация;

- прогнозирование;

- ассоциация;

- визуализация.

С помощью статистических методом обобщаются классифицируются первичные результаты. Целью прогнозирования является предсказание будущих зависимостей между зависимыми и независимыми переменными

Интеллектуальный анализ данных способствует построению адекватной модели, по обработке, выявлению и созданию необходимой информации в части логистических затрат экономического субъекта.

Одним из современных методов оценки логистических затрат является Метод искусственных нейронных сетей (ИНС). Впервые данный метод был предложен американским ученым Д. Баурсоксом. С помощью данного метода можно комплексно анализировать влияние факторов на результативный показатель- уровень логистических затрат [3].

Сложность в применении данного подхода заключается в отсутствии общепринятой структуры логистических затрат в экономическом субъекте.

Так же необходимо определить удельный вес логистических затрат в структуре всех затрат экономического субъекта.

Укрупненный анализ логистических затрат показал, что расходы на управления запасами

Таблица 1. Методы анализа логистических затрат экономического субъекта

\begin{tabular}{|l|l|l|}
\hline \multicolumn{1}{|c|}{ статистические } & \multicolumn{1}{c|}{ кибернетические } & \multicolumn{1}{c|}{ аналитические } \\
\hline дескриптивный анализ & искусственные нейронные сети & классические методы \\
\hline корреляционный анализ & эволюционное программирование & факторный анализ \\
\hline регрессионный анализ & генетические алгоритмы & экономико-математический метод \\
\hline дисперсионный анализ & ассоциативная память & графические методы \\
\hline компонентный анализ & нечеткая логика & \\
\hline дискриминантный анализ & деревья решений & \\
\hline анализ временных рядов & $\begin{array}{l}\text { системы обработки экспертных } \\
\text { данных }\end{array}$ & \\
\hline
\end{tabular}


составляют 20-40\%, расходы на транспортные операции 15-35\%, расходы на администрирование логистики 9-14\% [4].

Международный опыт свидетельствует о том, что логистические затраты необходимо структурировать и классифицировать по местам их возникновения и функциональной принадлежности в цепи поставок. Так же необходимо учитывать в структуре затрат показатель потери прибыли от логистических рисков, и выделить в отдельную группу трансакционные затраты. На рис. 1 представлена структура общих логистических затрат.

При рассмотрении внутренней структуры искусственного нейрона и то, как он преобразует поступающий на его входы сигнал (информацию) х, мы пришли к заключению о возможности построения алгоритма оценки логистических затрат с помощью метода искусственных нейронных сетей.

Каждый нейрон имеет входы, через которые он принимает сигнал. Сигнал умножается на со- ответствующий вес, до n-входа. Затем все произведения суммируются.

\section{$\mathrm{x}_{1} \mathrm{w}_{1}+\mathrm{x}_{2} \mathrm{w}_{2}+\cdots+\mathrm{x}_{\mathrm{n}} \mathrm{w}_{\mathrm{n}}=\sum \mathrm{x}_{\mathrm{i}} \mathrm{w}_{\mathrm{i}}$}

Результат работы сумматора- взвешенная сумма, то есть сумма входных сигналов, умноженная на соответствующие им веса.

\section{net $=\sum \mathrm{x}_{\mathrm{i}} \mathrm{w}_{\mathrm{i}}$}

Сумматор агрегирует все входные сигналы в одну взвешенную сумму, характеризующую поступивший на нейрон сигнал.

Математическая модель искусственного нейрона с n-входами:

\section{out $=\phi\left(\sum \mathrm{x}_{\mathrm{i}} \mathrm{w}_{\mathrm{i}}\right)$}

Для модели искусственного нейрона:

$\mathrm{x}_{1}$ - затраты на транспортировку;

$\mathrm{x}_{2}$ - затраты на складирование;

$\mathrm{x}_{3}$ - затраты на администрирование и трансакционные затраты;

$\mathrm{x}_{4}$ - потери прибыли от логистических рисков.

Поэтому на рис.3 представим модель искусственного нейрона анализа логистических затрат.

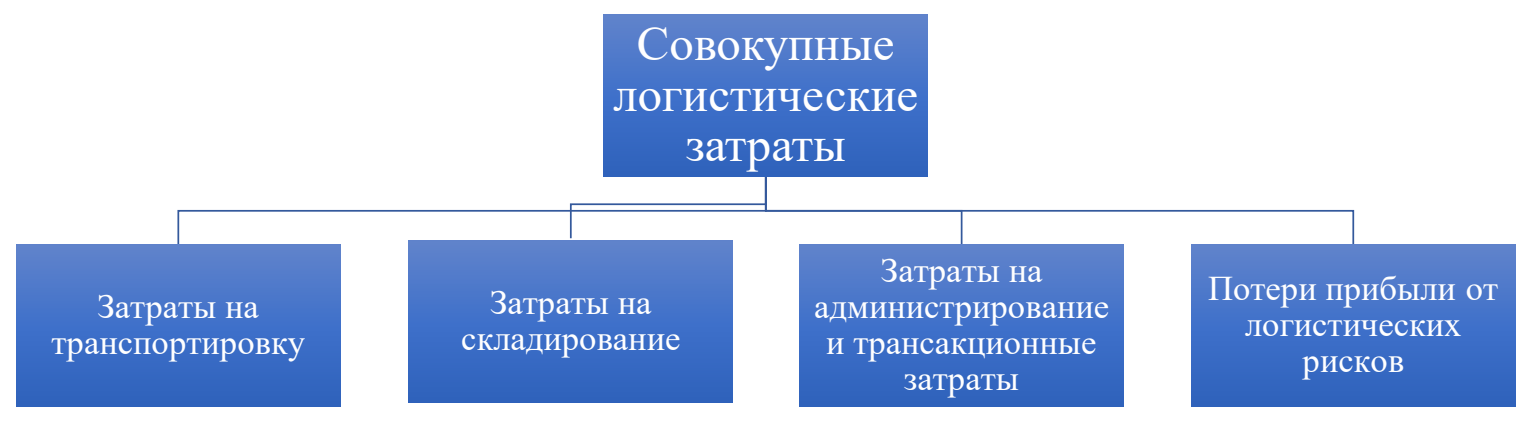

Рисунок 1. Структура общих логистических затрат

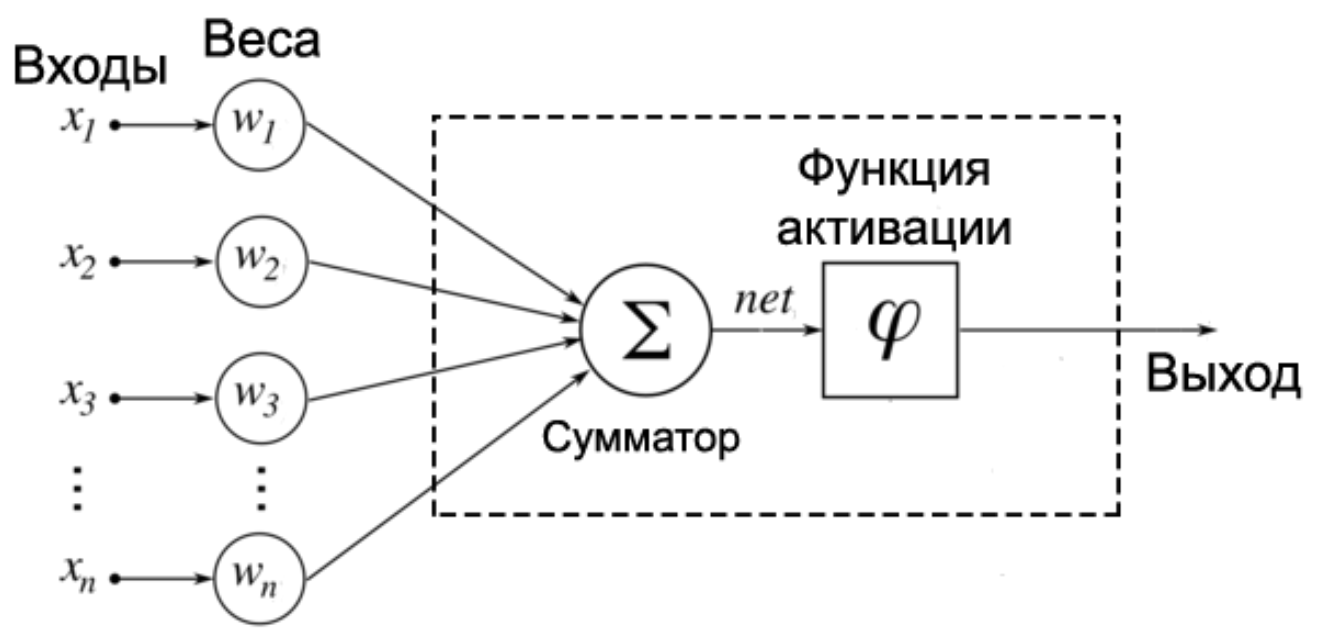

Рисунок 2. Модель искусственного нейрона [5] 


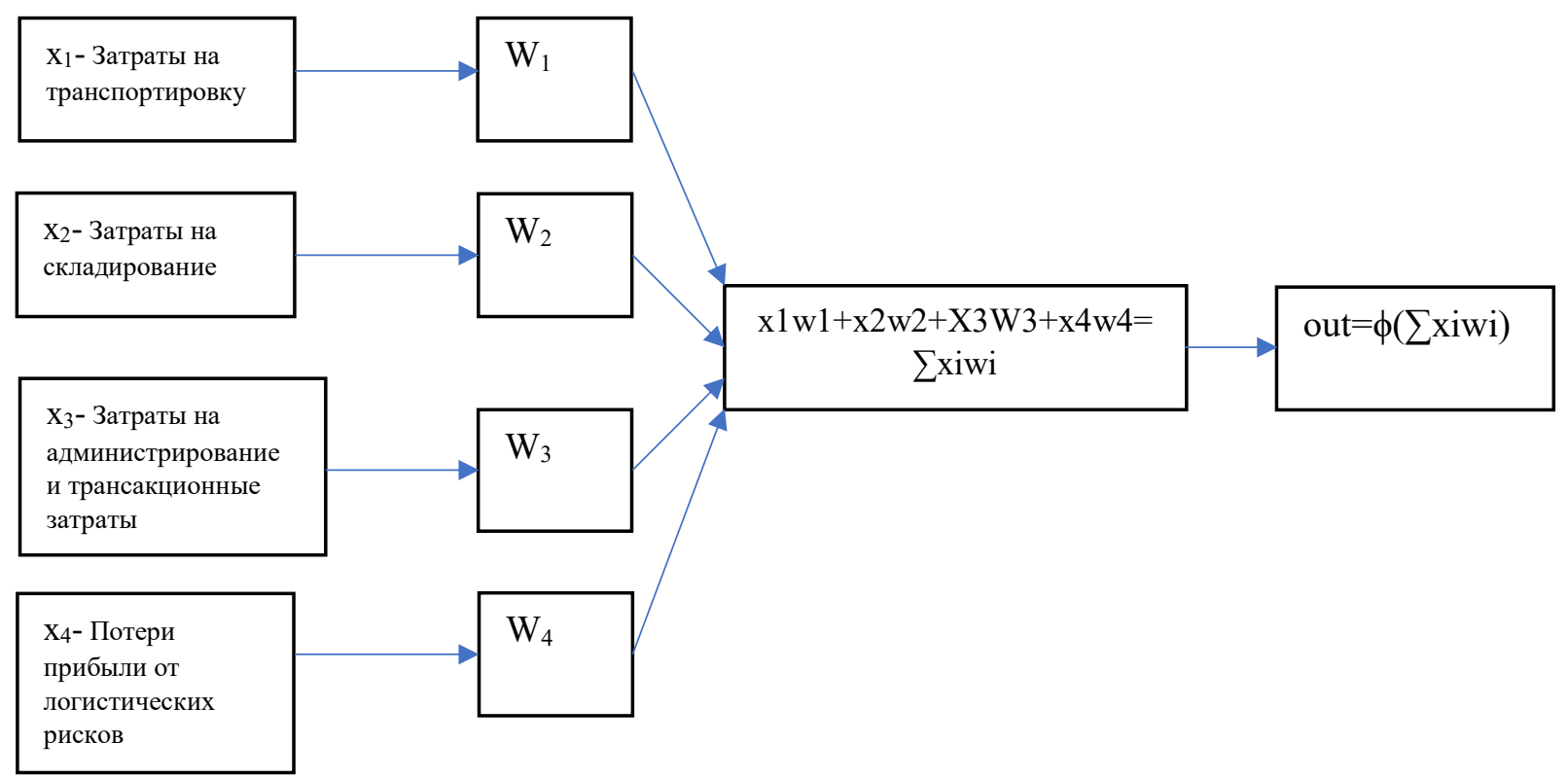

Рисунок 3. Модель искусственного нейрона анализа логистических затрат

Так же к современным методам оценки логистических затрат можно отнести метод множественной регрессии, представляющий собой регрессию результативного признака с двумя и большим числом факторов, то есть модель вида

$$
y=\hat{f}\left(x_{1}, x_{2}, \ldots x_{n}\right)[6] .
$$

Значение результатов деятельности экономического субъекта складывается под воздействием многих факторов, в свою очередь построение модели многофакторного регрессионного анализа логистических затрат способствует определению не только степени влияния факторов на обобщающий показатель, но и моделировать значение обобщающего показателя, задавая значения того или иного фактора.

Предложим уравнение множественной регрессии анализа логистических затрат:

$\mathrm{y}=\mathrm{a}_{0}+\mathrm{a}_{1} \mathrm{x}_{1}+\mathrm{a}_{2} \mathrm{x}_{2}+\ldots+\mathrm{a}_{\mathrm{i}} \mathrm{x}_{\mathrm{i}}+\ldots+\mathrm{a}_{\mathrm{n}} \mathrm{x}_{\mathrm{n}}$

y - результативный показатель или суммарные логистические затраты;

x - факторы, оказывающие влияние на результативный показатель (логистические затраты по видам);

a - коэффициенты регрессии, показывающие степень влияния факторов на результативный показатель.

Таким образом, все рассмотренные выше подходы для оценки логистических затрат, должны быть адаптированы для российской экономики.

Основываясь на зарубежном опыте, можно говорить о том, что для проведения оценки логистических затрат необходима общепринятая классификация по месту их возникновения и функционирования в логистической цепи.

Логистика, в части цифровизации, отстает от многих сфер деятельности. Недостаточная гибкость и прозрачность логистических операций является препятствием на пути интеграции логистических процессов.

Цифровизация логистики должна базироваться на создании надежной внутренней цифровой основы в организациях, внедрении новых бизнес-моделей, что позволит сделать логистические цепи более устойчивыми, позволит более эффективно использовать транспортную инфраструктуру, сократить уровень загрязнения окружающей среды.

Цифровая логистика позволит найти мультимодальные решения в области управления экономическими процессами, опираясь на современные методы оценки логистических затрат.

Применение инструментов цифровой логистики ведет к инновационному развитию транспортных систем. 


\section{Библиографический список}

1. www.eurasioncommiesion.org/ru

2. Мартин Браун. Методы интеллектуального анализа данных/Information Management. https://www.ibm.com/ developerworks/ru

3. Бауэрсокс Доналд Дж., Клосс Дейвид Дж. Логистика: интегрированная цепь поставок. 2-изд./ [Пер. с англ. Н.Н. Барышниковой, Б. С. Пинскера].- М.: ЗАО «Олимп-Бизнес», 2008.-640с.

4. Козлов В.К., Царева Е.С. Экономическое содержание логистического потока: учет и анализ// научно- аналитический журнал: Логистика и управление цепями поставок. № 3(80). Июнь, 2017.

5. https://ru.wikipedia.org/wiki/Искусственный_нейрон

6. Кремер, Н.Ш. Эконометрика: учебник и практикум для академического бакалавриата / Н.Ш. Кремер, Б.А. Путко: под ред. Н.Ш. Кремера. - 4-е изд., испр. и доп.-М.: Издательство Юрайт, 2018. - 354c. 